\title{
A LINGUAGEM NA PERSPECTIVA DE JOHN LOCKE: INTERSEÇÕES COM A NEUROCIÊNCIA E UMA POSSÍVEL CONTRIBUIÇÃO PARA O ENSINO DE CIÊNCIAS
}

\section{THE LANGUAGE IN A JOHN LOCKE PERSPECTIVE: INTERSECTION WITH NEUROSCIENCE AND A POSSIBLE CONTRIBUTION FOR SCIENCE LEARNING}

\author{
R. S. CARVALHO ${ }^{1, *}$, M. S. CARVALHO ${ }^{2}$
}

${ }^{1}$ Universidade Federal de Viçosa, Departamento de Química, Viçosa, Minas Gerais, Brasil

${ }^{2}$ Faculdade de Medicina, Campos, Rio de Janeiro, Brasil

${ }^{*}$ Corresponding author. Universidade Federal de Viçosa, Department of Chemistry, Viçosa, Minas Gerais, Brazil, Phone: +55 3138994886

e-mail address': resicar@ufv.br (R. S. Carvalho).

\begin{tabular}{l} 
A R T I C L E I N F O \\
\hline Article history: \\
Received: 2018-01-23 \\
Accepted: 2018-03-22 \\
Available online: 2018-06-30 \\
pa lavras-chave \\
Linguagem \\
John Locke \\
Neurociência \\
Ensino de Ciências \\
ke yw or $d s$ \\
Language \\
John Locke \\
Neuroscience \\
Science teaching
\end{tabular}

\begin{abstract}
A B S T R A C T
In this work are introduce some ideas of empiricist John Locke about language and how this perspective is seen in the look of the neuroscience. Language, as a human construct, permeates the discursive interactions and is fundamental in the construction of concepts. Many brain regions are enabled during process of language some of them are priority for our knowledge and understanding of this phenomena. The objective of this essay is make a intersection of the ideas of John Locke and the neuroscience perspective in a spite of the long time between them. At last this article point the contribution of John Locke ideas for the science learning, especially when he argue about concept formation by the child.
\end{abstract}

R E S U M O

Nesse trabalho são abordadas algumas ideias do filosofo empirista, John Locke, sobre a linguagem e, como essa é abordada do ponto de vista da neurociência. A linguagem, enquanto construto humano, permeia as interações discursivas e é fundamental na construção de conceitos. Diversas regiões do cérebro são ativadas no processo linguístico, sendo algumas delas prioritárias. Nesse ensaio objetiva-se tecer interseções a respeito da linguagem do ponto de vista da neurociência e do John Locke, apesar do intervalo de tempo de mais de 300 anos existente entre eles. E, finalmente, visa também apontar a contribuição das ideias de John Locke para o ensino de ciências, especialmente quando esse autor discute a formação de conceitos pela criança. 


\section{INTRODUÇÃO}

No processo educacional busca-se incessantemente uma comunicação efetiva que implica um entendimento satisfatório entre o falante e o ouvinte (receptor). Deseja-se que o aluno entenda o que o professor diz, que o professor entenda o que o aluno diz, que os colegas de sala se entendam, ou seja que haja entendimento nas trocas discursivas.

Com relação ao estudo das ciências, pretende-se também que o aluno vá adquirindo a linguagem científica à medida que se apropria dos conceitos científicos e lhes atribui significados.

A linguagem, construto humano, tem recebido a atenção de filósofos e pensadores e, atualmente, a neurociência tem contribuído para uma nova perspectiva do tema, através do desenvolvimento de exames e técnicas que permitem visualizar, durante o processo de comunicação, áreas do cérebro que são ativadas e estimuladas por esse tipo de ação.

O filosofo John Locke discute vários aspectos da linguagem que apresentam intercessões com a neurociência e remete-nos a tecer reflexões que podem vir a contribuir para amenizar as dificuldades que nossos alunos apresentam na aprendizagem de conceitos científicos.

\section{METODOLOGIA}

Esse estudo de natureza qualitativa e exploratória utilizou-se da pesquisa bibliográfica. $\mathrm{O}$ levantamento bibliográfico foi feito a partir das obras de John Locke, artigos e livros sobre o assunto com intuito de responder as questões relativas as aproximações das ideias deste autor e a visão atual da neurociência, e a possível contribuição para o ensino das ciências.

\section{A LINGUAGEM SEGUNDO JOHN LOCKE}

John Locke, empirista do século XVII (1632- 1704), em sua obra mais famosa: "Ensaio sobre o entendimento humano" publicada em 1690, traz que Deus deu ao homem a faculdade de falar para que este fizesse uso da linguagem para socialização. Se para cada uma das coisas do universo fosse atribuído um nome particular seria impossível o uso da linguagem devido a imensa quantidade de palavras que seriam necessárias. O aperfeiçoamento da linguagem implica no emprego de termos gerais que podem significar várias coisas particulares, "a função das palavras é serem marcas sensíveis das ideias, e as ideias que elas representam constituem a sua significação própria e imediata" (LOCKE, 1999, p. 545).

Esse filósofo exemplifica a significação das palavras descrevendo uma criança que tenha visto o metal ouro. Primeiramente, a criança atribuiria o significado do ouro, à brilhante cor amarela, mas à medida que intensificasse a experiência com o material poderia associar ao metal, a ideia de grande peso, fusibilidade e maleabilidade.

Para esse autor, um homem usa uma palavra para se comunicar com o outro se essa tem significado para ele e, a comunicação será eficiente, se o significado para aquele que a escuta (recebe) seja o mesmo.

Já a definição de uma palavra seria a explicação da mesma por meio de várias outras que não sejam sinônimas.

As palavras são gerais quando são usadas como sinais de ideias gerais e podem ser aplicadas a várias coisas particulares, e as representam. As ideias gerais, diferentemente das ideias simples, são obras do entendimento e obtidas por abstração.

As essências das coisas são também obra do entendimento. As qualidades, a constituição das substâncias são a sua essência. As essências são imutáveis, e possui um nome associado as ideias que inspiram e lhe dão o significado.

Para Locke (1999) as ideias simples não podem ser entendidas pela definição do nome dessa, mas somente pela impressão. Em seu ponto de vista, não há como um cego ter a ideia da luz e da transparência, simplesmente pela definição. Ele saberá a definição, mas não terá o entendimento. Cita como exemplo, de que palavras não seriam suficientes para descrever o sabor de um ananás, sem a pessoa tê-lo experimentado, haveria no máximo uma aproximação mental se esta pessoa tivesse experimentado outros sabores.

As ideias complexas, por sua vez, são formadas por várias ideias simples e podem ser definidas por palavras. $\mathrm{O}$ espirito humano escolhe um certo número de ideias, depois estabelece ligações entre elas e as reúne em uma nova ideia. Portanto são frutos da "criação humana" (LOCKE, 1999, p.584). "Embora seja o espírito que forma a combinação, é o nome o nó que as mantém estreitamente unidas (LOCKE,1999, p. 590, grifo nosso)

Locke alertava também para as dificuldades de tradução, considerando que havia muitas palavras em uma língua que não poderiam ser traduzidas em outras, e que mesmo com a definição nos dicionários, dificilmente se conseguiria a mesma ideia da palavra originalmente traduzida.

O homem para exprimir os seus pensamentos deve observar a dependência dos seus raciocínios e utilizar bem as palavras que mostrem a conexão desses raciocínios. À essas palavras de conexão ele atribui o nome de partículas.

Locke afirma que:

O principal fim da linguagem, na comunicação, é o de ser entendido, e, por isso, as palavras não serviriam bem para esse fim, nem no discurso social nem no filosófico, quando uma palavra não excitasse no espírito daquele que a escuta a mesma ideia que significa no espírito daquele que fala. (LOCKE, 1999, p. $650)$.

Outro ponto bastante interessante discutido por Locke, refere-se ao aprendizado pelas crianças de palavras referentes a conceitos mais abstratos. A seu ver, as crianças aprendem primeiros os sons e depois elas ficam dependentes da explicação de outros para o significado daquelas palavras ou podem obtêlas pela observação e sagacidade. Mas o real significado ficará 
a desejar, principalmente palavras referentes à moral. A consequência disso é que ao se debater sobre honra, fé, igreja, etc., os homens apresentarão, comumente, diferentes noções.

Ainda, de acordo com Locke, além da imperfeição da linguagem o mau uso desta pelos próprios homens causam ainda mais confusão. Há discursos que a mesma palavra é usada com significados diferentes, outras novas que são usadas sem uma predefinição e assim por diante.

Locke fez a seguinte indagação;

[...] não seria mais conveniente para os homens [...] que o uso das palavras se tornasse simples e direto e que a linguagem, feita para aperfeiçoamento do saber e para facilitar as relações sociais, não fosse em vez disso empregada para escurecer a verdade e confundir os direitos dos povos, e para levantar névoas e tornar, tanto a moral como a religião, ininteligíveis? (LOCKE, 1999, p. 678).

E encerra o capítulo $X$, da sua obra anteriormente citada, intitulado: "do abuso das palavras", com a seguinte frase; "A eloquência, como o belo sexo, tem encantos muito poderosos para permitir que se fale contra ela. É em vão que se descobre o erro dessas artes enganosas pelas quais os homens têm prazer em ser enganados." (LOCKE, 1999, p. 693).

\section{CONTRIBUIÇÃO DA NEUROCIÊNCIA}

A comunicação não é exclusiva dos homens já que os animais se comunicam, mas a construção e o uso da linguagem são humanos. A linguagem é estudada por linguistas, neurolinguistas, psicolinguistas, entre outros e é consenso que esta permite a comunicação entre pessoas que compartilham a mesma língua e que estabelece uma relação entre o símbolo e o referente. A linguagem possuiu uma estrutura em diferentes níveis e é dinâmica, pois as línguas evoluem (STERNBERG, 2008).

Toda palavra é um símbolo e este representa alguma coisa, e a simbologia das palavras são feitas por convenções (STERNBERG, 2008).

"A compreensão verbal é a capacidade receptiva de compreender inputs linguísticos recebido escritos ou falados, como palavras, sentenças e parágrafos (STARR E RAYNER, 2003 apud STERNBERG, 2008, p. 298) e a fluência verbal é a capacidade expressiva de emitir outputs linguísticos.

Atualmente, assume-se que a aquisição da linguagem envolve um dom natural modificado pelo ambiente e que os bebes têm capacidades de aprendizagem de linguagem. Os seres humanos desenvolvem a linguagem por estágios. Primeiramente, o balbucio inarticulado, seguido do articulado, enunciado de uma palavra, duas palavras e sentenças. Aos 18 meses as crianças têm vocabulários entre 3 e 100 palavras, logo os seres humanos devem estar biologicamente pré-configurados para adquirir linguagem (STERNBERG, 2008).

A relatividade linguística considera que os falantes de diferentes línguas têm sistemas cognitivos distintos e que esses sistemas cognitivos influenciam as formas como as pessoas que falam as várias línguas pensam sobre o mundo (STERNBERG, 2008).

As culturas têm padrões característicos de linguagem. Muitos desses universais linguísticos estão relacionados à fonologia, à morfologia, à semântica e à sintaxe. As diferenças estruturais sintáticas, bem como semânticas podem afetar o pensamento. Por exemplo, a língua espanhola utiliza as formas ser e estar em contextos diferentes.

Lesões cerebrais podem afetar as funções linguísticas. As afasias, por exemplo, são déficits de linguagem adquiridos pós lesão e as primeiras identificadas foram a de Broca e a de Wernicke.

Pierre Paul Broca depois de estudar inúmeros casos de pacientes que, sem ter danos nos músculos da face haviam perdido a capacidade de falar, delimitou, em 1863, uma área no lobo frontal do hemisfério esquerdo do cérebro como diretamente associada à produção de linguagem, à fala. (LENT, 2010). Essa afasia caracteriza-se pela produção de fala agramatical (STERNBERG, 2008).

Karl Wernicke, neurologista alemão, concluiu, após o estudo de pacientes que haviam sofrido Acidente Vascular Encefálico (AVE), que uma área específica no lobo temporal do hemisfério esquerdo do cérebro estaria relacionada à compreensão, à recepção de linguagem, e em 1874 foi nominada Área de Wernicke (LAGE, 2013). A afasia de Wernicke caracteriza-se por prejuízos no entendimento de palavras e sentenças faladas (STERNBERG, 2008). O estudo sobre essa afasia tem sido aprofundado e parece envolver áreas vizinhas.

A Figura 1 apresenta a localização da área de Broca e da área de Wernicke.

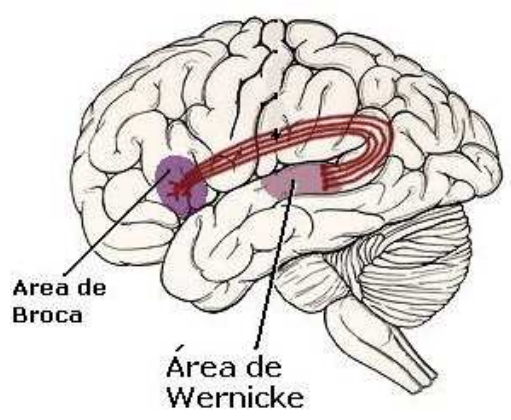

Figura 1 - Área de Broca e Wernicke.

Fonte: goo.gl/5P2N13 (modificado pelos autores)

Crianças com espectro autista podem também apresentar problemas com linguagem.

\subsection{A linguagem}

$\mathrm{O}$ contato com a linguagem pode ser por via oral e auditiva, visual, através da leitura, ou pelos movimentos no caso de surdos, táctil quando se usa Braille ou de formas conjuntas.

Durante a comunicação falada o som do orador se propaga pelo ar e é captado pela membrana timpânica do ouvinte. Essa membrana vibra conforme as características do som captado no meio externo e estimula a movimentação dos 
ossículos no ouvido médio que levam esse estimulo mecânico a cóclea localizada no ouvido interno, onde células eletromecanicamente sensíveis traduzem essas vibrações em impulsos nervosos. Esses impulsos de natureza elétrica são levados até o córtex onde os sons se tornam inteligíveis e sua compreensão é gerada (GUYTON, HALL, 2011).

O eletroencefalograma se tornou um método de leitura de impulsos elétricos, sendo capaz de fazer o mapeamento cerebral e identificar doenças neurológicas e distúrbios de condução.

As técnicas hemodinâmicas, por sua vez, baseiam-se na intensidade do fluxo sanguíneo. Os neurônios que participam da tarefa cognitiva, se exercitam e precisam de quantidades maiores de glicose e de oxigênio que são levadas pelo sangue. As técnicas hemodinâmicas mais utilizadas são a Tomografia por Emissão de Pósitrons (PET) e a Imagem por Ressonância Magnética Funcional (fMRI) (LAGE, 2013). Por exemplo, Fontoura et al (2008) investigaram a dominância cerebral para linguagem em sujeitos normais e em epilépticos através da fMR e concluíram que $94 \%$ dos sujeitos normais demonstraram hemisfério esquerdo dominante para linguagem e nos sujeitos com epilepsia, $78 \%$.

A PET tem sido utilizada para determinação de áreas relacionadas com alguma atividade cerebral. A figura 2 apresenta imagens obtidas por PET que indicam aumento da atividade neural quando o indivíduo desempenha as diferentes ações.

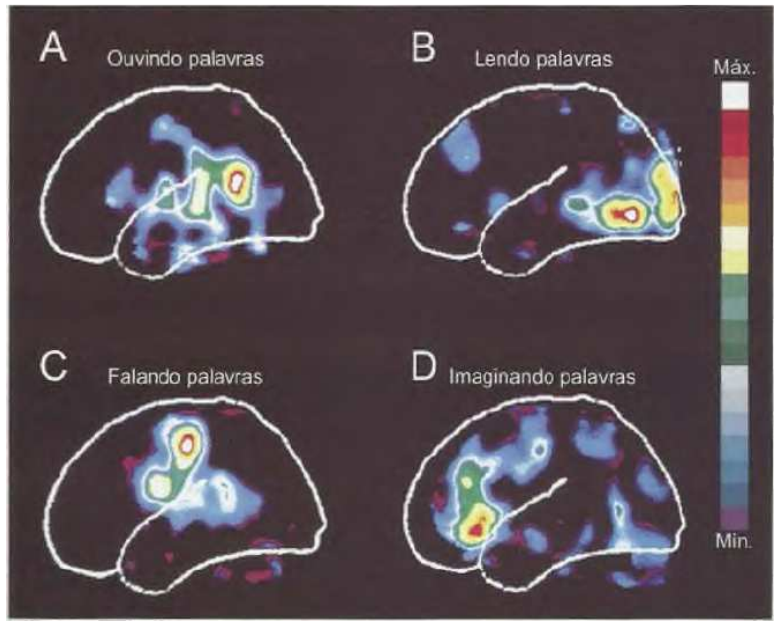

Figura 2: Áreas cerebrais envolvidas com a linguagem (LENT, 2010, p. 685)

A neuropsicologia entende que toda e qualquer função cognitiva é, um sistema funcional complexo, cuja característica principal é a interação e o funcionamento em conjunto de diversas zonas cerebrais, sendo que cada zona cerebral individual contribuiria com um fator específico ao processo. Não recomendam a adoção da posição localizacionista e nem a posição unitarista, que assume que as formas complexas de atividade mental estariam relacionadas ao funcionamento de todo o cérebro (DE TONI et al, 2005).

Segundo Lent (2010), os psicolinguistas consideram que a construção das frases começa com a conceitualização, uma ação mental nominada macroplanejamento. As regiões cerebrais envolvidas seriam as conceitualizadoras e fariam a busca no léxico semântico. O microplanejamento envolveria a formulação, a busca por palavras, fonemas e regras sintáticas e as regiões cerebrais envolvidas seriam as formuladoras provavelmente localizadas na área de Broca. A articulação, emissão da fala, uma tarefa motora envolve as regiões do córtex frontal esquerdo e os setores da face.

Outros quesitos fundamentais são a prosódia que corresponde as inflexões de voz, e a pantomina, mímica facial e os gestos das mãos e do corpo, que são os aspectos emocionais da fala. A prosódia, na maioria das pessoas, ativa o hemisfério direito do cérebro. Vygotsky (1896 - 1934), psicólogo do século passado já indicava que "uma compreensão plena e verdadeira do pensamento de outrem só é possível quando entendemos sua base afetivo-volitiva" (2008, p.186)

\section{ALGUMAS REFLEXÕES}

Wittgenstein (apud CONDÉ, 2004) aponta que a significação da palavra é determinada pelo uso. Para Locke (1999) o uso determina o sentido das palavras para a conversa comum, mas não para a filosofia. Para essa última os termos precisam ser definidos com mais precisão.

Para exemplificação dessa concepção de Locke, em um trabalho recente sobre ensino de física, Filippini (2017) relata a dificuldade de alunos do Ensino Médio entenderem a diferença conceitual entre as palavras sentido e direção no contexto da física. Na linguagem coloquial e nos dicionários de língua portuguesa as palavras, sentido e direção possuem o mesmo significado, diferindo do conceito científico.

Atualmente acredita-se que há uma pré-configuração biológica para que os seres humanos adquiram a linguagem (STERNBERG, 2008), Locke (1978, p.48) já afirmava que “[...] a capacidade é inata, mas o conhecimento adquirido".

A relatividade linguística apontada por Sternberg (2008) é abordada por Locke em duas passagens; quando relata o caso em que um cidadão se apropriara de duas palavras novas e lhes atribuiu significados diferentes, conforme as suas vivências, e ao mencionar que as palavras: hora, pés e libra são facilmente traduzidas para o inglês, mas a ideias que os romanos têm das palavras são diferentes das ideias que os ingleses têm das palavras em inglês.

Locke não trata diretamente da prosódia, mas alerta quanto à sedução da eloquência. Mikhail Bakhtin (1895 -1975) posteriormente, aprofundará o estudo do caráter comunicativo da linguagem (MOLON, VIANNA, 2012).

Lent (2010, p. 670), por sua vez, corrobora o pensamento de John Locke afirmando que registramos com mais facilidade na memória acontecimentos com forte componente emocional, positivo ou negativo.

O abade francês Ètienne Bonnot de Condillac (17151780) aprofundou os estudos de Locke enfatizando a origem da linguagem. Para Condillac todas as ideias provinham das sensações e o homem precisava dos signos e da linguagem para o desenvolvimento das operações da alma. Ambos concordavam que as ideias simples eram a base do pensamento. Os signos, para Condillac deveriam ter uma analogia com os signos naturais (ADELL, 2016). Para esse autor todos os hábitos do corpo passam pelo cérebro e as fibras que o compõem adquirem o hábito de obedecer aos diferentes estímulos ocasionados pelos objetos (CONDILLAC, 1978). 


\section{CONSIDERAÇÕES FINAIS}

São várias as aproximações que se observa no pensamento de John Locke e a da neurociência.

A nosso ver o processo de conceitualização é que pode contribuir com mais eficácia para o ensino das ciências. A construção dos conceitos científicos depende de um perfeito uso das palavras e a troca de significados deve ser plena.

O processo de formação de uma ideia complexa que gerará um novo conceito a partir das ideias simples, colocado por John Locke, aponta um interessante caminho que devemos trilhar para trabalhar com nossos alunos, principalmente na formulação de novos conceitos. Ou seja, as ideias simples devem ser comuns, isto quer dizer, terem o mesmo significado para que se forme a ideia complexa com a reunião daqueles significados. Um conceito que não é construído se perde e não se fixa na memória, não há apreensão do mesmo.

De certa forma, quando buscamos os conceitos prévios dos alunos, oportunizamos que se aflorem as primeiras ideias, mas é oportuno que aprofundemos nesse mergulho, para construir os novos conceitos a partir do conhecimento dessas ideias prévias. O cuidado com a relatividade linguística e o exercício de definir as palavras ao usá-las, para que não haja entendimento inadequado deve ser incentivado nas interações discursivas em sala de aula.

Concordamos ainda com Locke, quanto ao uso de uma linguagem simples e direta, sem excesso de verbalismos, que contribui para um melhor entendimento dos conceitos.

No cotidiano de nossas aulas, não podemos esquecer que a linguagem e o conhecimento são construções humanas e a concepção da transitoriedade deve permear a educação científica.

Quanto a neurociência, ainda se almeja estudos comprobatórios relacionando a educação científica com a mesma. A medida que os novos exames, como as técnicas hemodinâmicas e o eletroencefalograma, são capazes de indicar quais áreas do cérebro são ativadas e relacionam-se com as informações da linguagem e quais são responsáveis pelo processamento de conceitos abstratos, pode-se pensar futuramente em estudos, mais completos envolvendo estudantes voluntários, durante suas atividades cognitivas.

R E F E R Ê N C IAS

ADELL, E. A. A. A linguagem e os signos nas teorias do conhecimento no Século das Luzes. Tese apresentada à Faculdade de Filosofia, Letras e Ciências Humanas da Universidade de São Paulo. São Paulo, 2016.

CONDÉ, M. L. L. As teias da razão: Wittgenstein e a crise da racionalidade moderna. Belo Horizonte: Argvmentvm, 2004.

CONDILLAC, E. B. Lógica ou os primeiros desenvolvimentos da arte de pensar. São Paulo: Abril Cultural, 1978. (Coleção Os Pensadores).

DE TONI, P. M.; ROMANELLI, E. J.; GUISANTES, S. A evolução da neuropsicologia: da antigüidade aos tempos modernos. Psicologia Argumento, Curitiba, v. 23, n. 41 p. 47-55, abr./jun. 2005.

FONTOURA, D. R.; BRANCO, D. M., ANÉS, M.; COSTA, J. C.; PORTUGUEZ, M. W. Identificação de regiões cerebrais de linguagem: estudo de ressonância magnética funcional em pacientes com epilepsia refratária de lobo temporal. Journal of Epilepsy and Clinical Neurophysiology, v.14, n.1, p.7-10, 2008.

GUYTON, A. C.; HALL, J. E. Tratado de Fisiologia Médica - 12 ed. Rio de Janeiro: Elsevier. 2011

FILIPPINI, A. S. Atividades Investigativas no Ensino de Hidrostática. Dissertação. Mestrado Nacional Profissional em Ensino de Física. Universidade Federal de Viçosa. Viçosa, 2017.

LAGE, A. C. Análise de novos dados linguísticos: a eletroencefalografia em neurociência da linguagem. Revista FSA, Teresina, v. 10, n. 1, art. 9, p. 153-172, Jan./Mar. 2013. Disponível em: http://dx.doi.org/10.12819/2013.10.1.9. Acesso em 18 de setembro de 2017.

LENT, R. Cem bilhões de neurônios? Conceitos fundamentais de Neurociência. 2. ed. Rio de Janeiro: Atheneu, 2010.

LOCKE, J. Carta acerca da tolerância; Segundo tratado sobre o governo; Ensaio acerca do entendimento humano. Tradução de Anoar Aiex e E. Jacy Monteiro. 2. ed. São Paulo: Abril Cultural, 1978. (Coleção Os Pensadores).

LOCKE, J. Ensaio sobre o entendimento humano. Lisboa: Fundação Calouste Gulbenkian, 1999.

MOLON, N. D.; VIANNA, R. O Círculo de Bakhtin e a Linguística Aplicada. Bakthniana, São Paulo, 7 (2): 142-165, Jul./Dec. 2012.

STERnBERG, R. J. Psicologia Cognitiva. 4.ed. Porto Alegre: Artmed, 2008.

VIGOTSKI, L. S. Pensamento e linguagem. 4.ed. São Paulo: Martins fontes, 2008. 